\title{
Hyperbaric oxygen as a chemotherapy adjuvant in the treatment of metastatic lung tumors in a rat model
}

\author{
Paul M. Petre, MD \\ Frank A. Baciewicz, Jr, MD \\ Stefan Tigan, $\mathrm{PhD}^{\mathrm{d}}$ \\ J. Richard Spears, MD ${ }^{\mathrm{c}}$
}
From the Cardiovascular Research Labora- tories, ${ }^{a}$ the Division of Cardiothoracic Sur- gery, ${ }^{b}$ and the Department of Internal Med- icine and Physiology, ${ }^{\mathrm{c}}$ Wayne State University, Detroit, Mich, and the Depart- doxorubicin also significantly decreased the number of lung metastases and the lung weight relative to doxorubicin alone $(P<.01$ and $P<.01$, respectively). The feasibility of arterialization of mixed venous blood $(>100 \mathrm{~mm} \mathrm{Hg})$ with aqueous oxygen infusion was demonstrated. ment of Computer Science and Biostatistics, Cluj University of Medicine, ${ }^{\mathrm{d}}$ Cluj, Romania.

Read at the Eighty-first Annual Meeting of The American Association for Thoracic Surgery, San Diego, Calif, May 6-9, 2001.

Received for publication May 14, 2001; revisions requested July 9, 2001; revisions received Dec 6, 2001; accepted for publication Dec 12, 2001.

Address for reprints: Frank A. Baciewicz, Jr, MD, Associate Professor of Cardiothoracic Surgery, Wayne State University, 3990 John R, Ste 2102, Detroit, MI 48201 (E-mail: fbaciewi@dmc.org).

J Thorac Cardiovasc Surg 2003;125:85-95

Copyright (C) 2003 by The American Association for Thoracic Surgery

0022-5223/2003\$30.00+0

doi: $10.1067 / \mathrm{mtc} .2003 .90$

Objectives: The objectives of the study were to test the hypothesis that hyperbaric levels of oxygen enhance the sensitivity of a sarcoma cell line to doxorubicin (Adriamycin) both in vitro and in vivo in a rat model of pulmonary metastases and to test the feasibility of arterialization of mixed venous blood by direct injection of aqueous oxygen into the pulmonary artery in a rat model.

Methods: Rat sarcoma (MCA-2) cells were incubated in the presence of increasing concentrations of doxorubicin $(0.1-2.0 \mu \mathrm{mol} / \mathrm{L})$. A dose-dependent toxicity relationship at 12 hours of treatment was examined with and without pretreatment with hyperbaric oxygen (3.7 atm absolute for 1.5-3.5 hours). In vivo, Sprague-Dawley rats $(n=24)$ were injected intravenously with $10^{6}$ MCA- 2 cells, and the lung tumors were allowed to mature for 14 days. At that time the animals were divided into four groups: control (no treatment), doxorubicin at $2 \mathrm{mg} / \mathrm{kg}$, hyperbaric oxygen (oxygen at $2 \mathrm{~atm}$ absolute for 30 minutes), and hyperbaric oxygen plus doxorubicin. Seven days after treatment, the numbers of lung nodules were counted and the lung weights were determined. In additional rats $(\mathrm{n}=7)$, aqueous oxygen $(1 \mathrm{~mL}$ oxygen/g saline solution) was infused into the pulmonary artery to determine whether arterialization of mixed venous blood was comparable to pulmonary artery oxygenation with a hyperbaric chamber $(\mathrm{n}=7)$.

Results: Hyperbaric oxygen plus doxorubicin produced significantly greater cytolysis of MCA-2 cells $(P<.01)$ than did doxorubicin alone. Hyperbaric oxygen plus

Conclusions: Hyperbaric oxygen enhanced the chemotherapeutic effect of doxorubicin both in cell culture and in the rat model. Aqueous oxygen infusion can be used to oxygenate mixed venous blood at levels similar to those obtained with the use of a hyperbaric chamber.

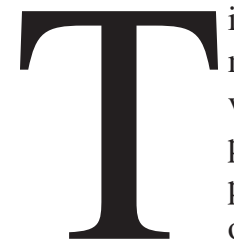

issue hypoxia contributes to the radioresistance of many tumors and may also reduce their sensitivity to some chemotherapeutic agents. A variety of approaches have been used to improve oxygen delivery in plasma, including the use of hyperbaric oxygen (HBO), hemoglobin preparations, and perfluorochemicals. ${ }^{1-5}$ The relatively high levels of oxygen deliverable with $\mathrm{HBO}$ make this approach attractive, and the results of many studies support the hypothesis that $\mathrm{HBO}$ reduces the radioresistance of certain types of tumors. Recent studies also suggest that HBO may enhance the efficacy of doxorubicin and alkylating agents in the treatment of hypoxic tumors. ${ }^{6-9}$

Application of $\mathrm{HBO}$ is limited by lack of control of $\mathrm{PaO}_{2}$, difficulties in treatment during exposure, middle ear barotrauma, expense, and availability. For patients with 


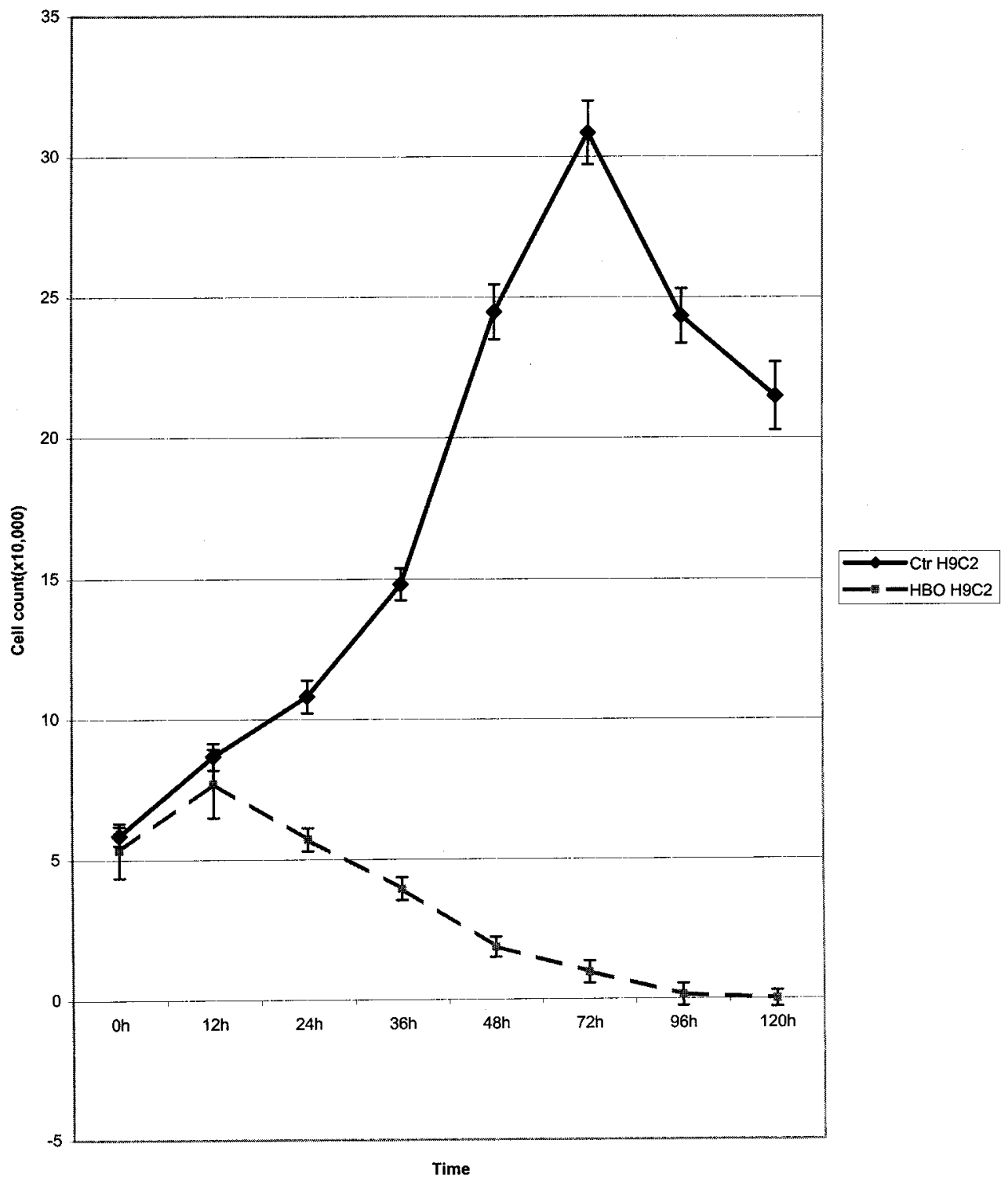

Figure 1. HBO effect on embryonic cardiac myocyte (H9C2) growth curves. Diamonds indicate normal growth curve in air; squares indicate reduced growth with toxic effect of HBO. Data points represent mean; error bars represent SE; number of observations $=29$.

lung tumors, tissue hypoxia may be a particular problem because of the dual factors of impaired respiratory function and perfusion of tissue with mixed venous blood.

We recently developed a new method for regional perfusion of tissues with blood oxygenated by intra-arterial infusion of aqueous oxygen. The miniature size of the capillary used to deliver aqueous oxygen, the physiologic interface for introduction of oxygen (saline solution and blood mixing), and the hyperbaric levels of oxygen achievable provide multiple potential advantages relative to conventional membrane oxygenators. ${ }^{10-11}$

These studies were designed to test the feasibility of the use of aqueous oxygen infusion for potential enhancement of conventional treatment of lung tumors. Sarcoma cell cultures and a rat model of sarcoma pulmonary metastases were studied to determine whether HBO potentiates the toxicity of doxorubicin.

\section{Methods}

\section{In Vitro Studies}

For the purpose of evaluating the effect of high levels of oxygen on culture cells, two cell lines were used: MCA-2, a highly undifferentiated rat-derived rhabdomyosarcoma cell line, and $\mathrm{H} 9 \mathrm{C} 2$, a line of embryonic rat-derived cardiac myocytes. The latter were also 


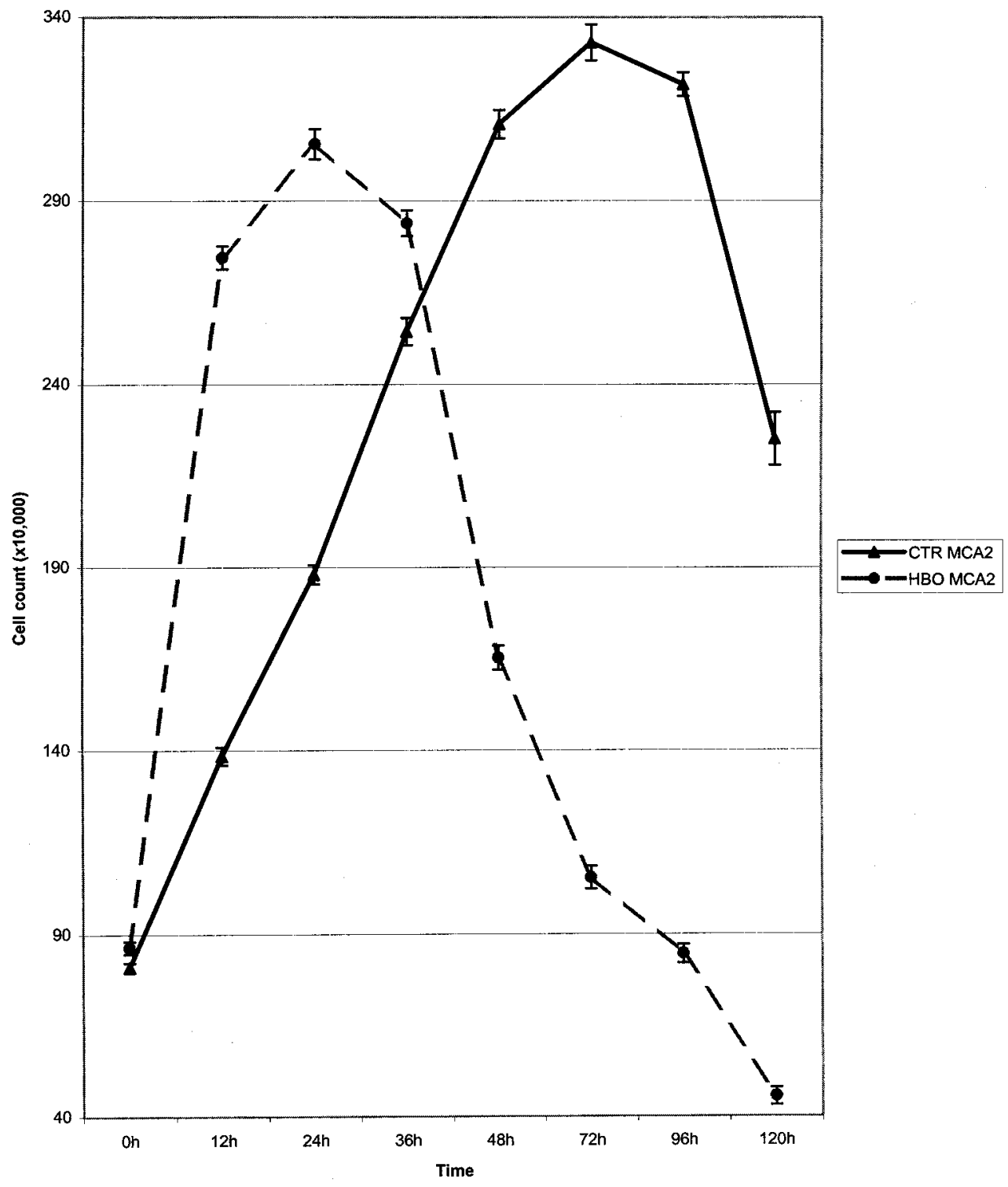

Figure 2. HBO effect on rat sarcoma cell (MCA-2) growth curves. Triangles indicate normal growth curve in air; circles indicate increased growth after 1.5 hours HBO for up to 36 hours. Data points represent mean; error bars represent SE; number of observations $=28$.

studied because of the known cardiac toxicity of doxorubicin. The cells were cultured in 6-well dishes at $37^{\circ} \mathrm{C}$, and normal growth curves were determined by counting cells at 12, 24, 36, 72, and 96 hours. Cells were counted with the Trypan blue exclusion method, and the results were plotted against time. The lactate dehydrogenase (LDH) activity in the culture medium was determined at the same times by spectrophotometry, which was also a reliable method of confirming the cell counts. ${ }^{12-14}$

After they reached $75 \%$ confluence, a group of cells from both populations were treated with HBO. For this purpose a hyperbaric chamber with multiple ports of access connected to an oxygen tank was used. The cells were placed inside the chamber, and oxygen at 40 psi was administered for either 1.5, 2.5, or 3.5 hours. After the procedure, the cells were immediately counted; cell counts and LDH determinations were also performed 12, 24, 36, 72, and 96 hours after initiation of HBO. Doxorubicin across a range of concentrations $(0.1-2 \mu \mathrm{mol} / \mathrm{L})$ was added to the culture medium, and the total number of cells and the LDH activity in the medium were assessed 12 hours after treatment.

To test the hypothesis that $\mathrm{HBO}$ may act as a chemosensitizer of tumor cells, an initial dose of HBO (1.5 or 3.5 hours at 40 psi) was administered to MCA-2 cells in the hyperbaric chamber. They were then immediately treated with increasing concentrations of doxorubicin (0.1-2 $\mu \mathrm{mol} / \mathrm{L})$. Cells were counted and LDH activity was measured 12 hours after treatment with doxorubicin. 
Doxorubic in dose-related response (MCA-2)
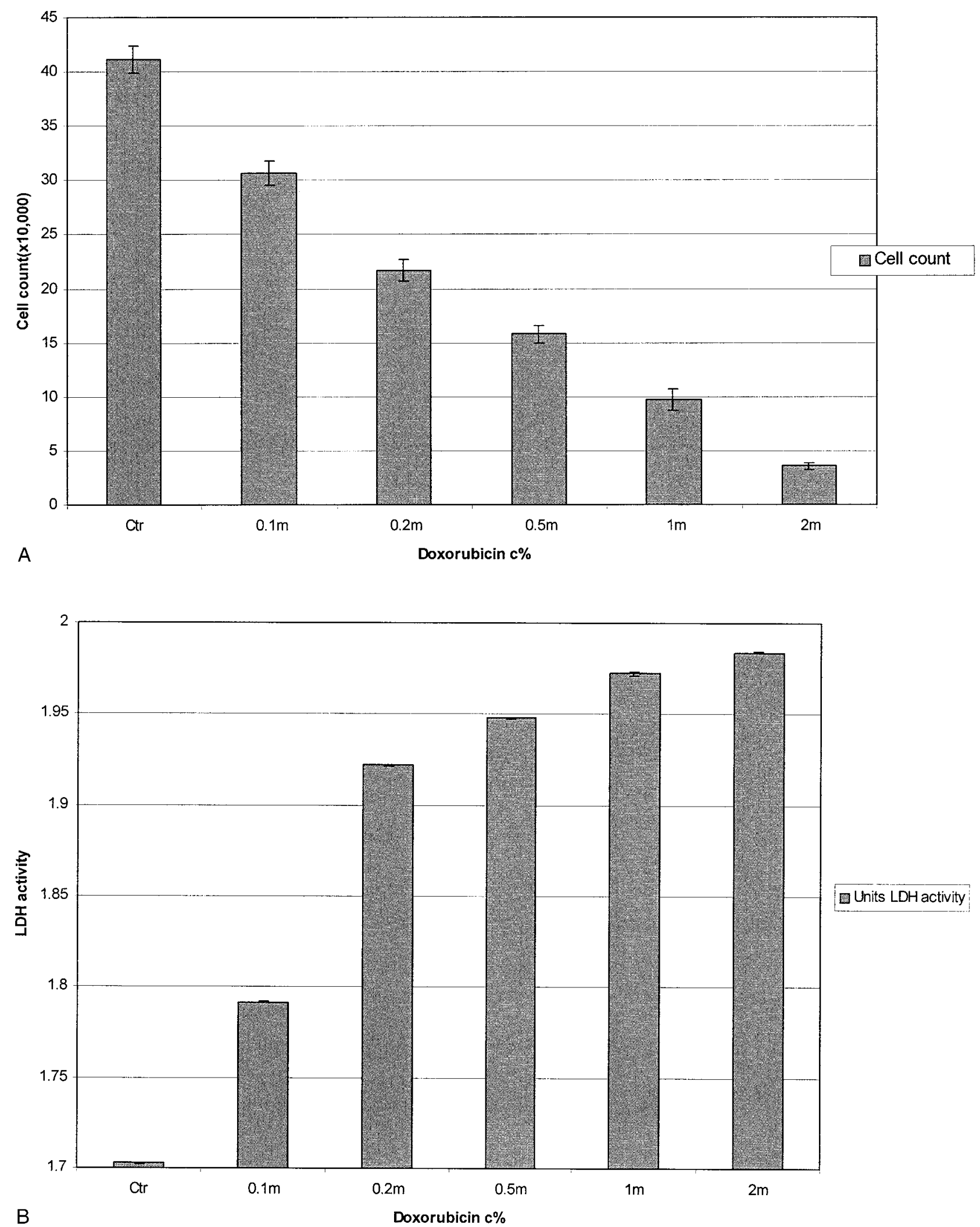

Figure 3. Dose-dependent responses of embryonic cardiac myocytes (H9CA) and sarcoma cells (MCA-2) to doxorubicin. A, Cell death of H9C2 cells even at minimal doxorubicin doses. B, LDH activity in H9C2 cells (which mirrors cell death) showed increasing activity with increasing doxorubicin doses. 
Doxorubicin related response $(\mathrm{H} 9 \mathrm{C} 2)$
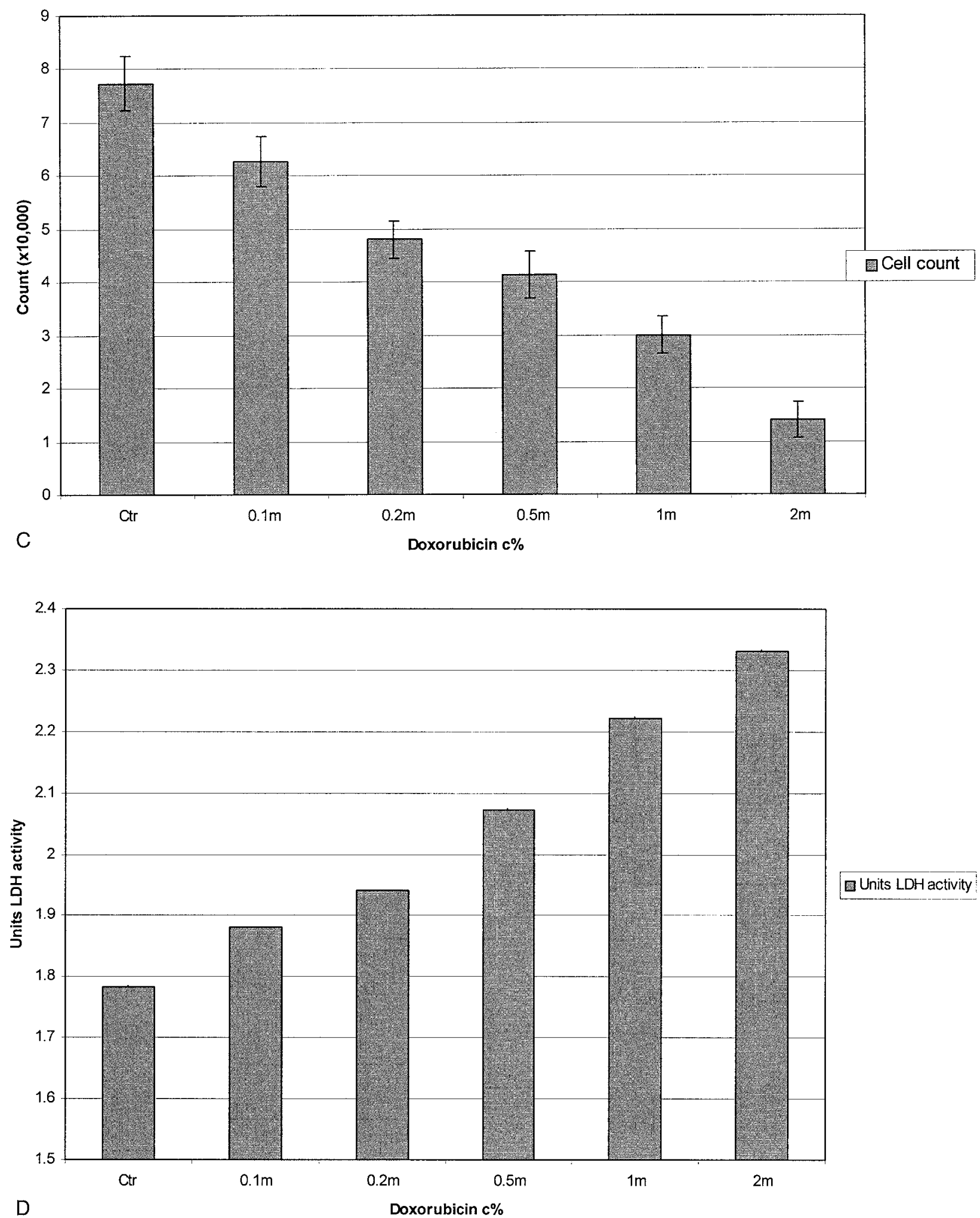

Figure 3. Cont'd. C, Cell death of MCA-2 cells even at minimal doxorubicin doses. D, LDH activity in MCA-2 cells (which mirrors cell death) showed increasing activity with increasing doxorubicin doses. Ctr, Control; m, micromolar; c\%, concentration. 


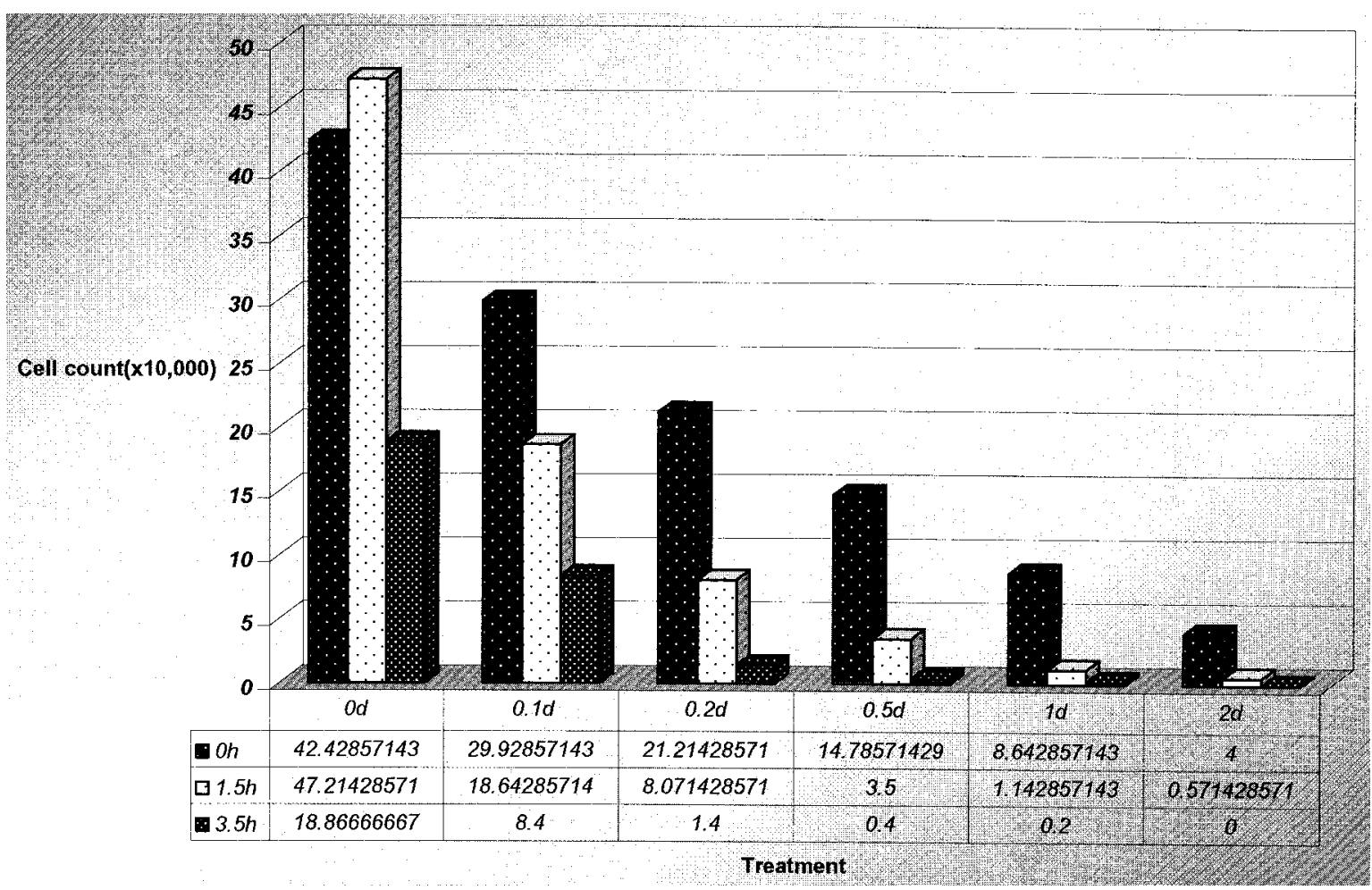

Figure 4. HBO as chemosensitizer. Cell counts with 1.5 hours of pretreatment HBO show enhanced sarcoma cell (MCA-2) death relative to treatment of sarcoma cells with doxorubicin only or pretreatment with 3.5 hours of HBO. $d$, Micromolar doxorubicin dose.

To gain insight into a potential mechanism by which HBO may sensitize cells to doxorubicin, MCA-2 cells were treated in advance with $0.2-\mu \mathrm{mol} / \mathrm{L}$ mitomycin, a drug known to block the cells in the $\mathrm{S}$ phase of the cell cycle. A single $0.2-\mu \mathrm{mol} / \mathrm{L}$ dose of mitomycin was followed by administration of $\mathrm{HBO}$ alone or in combination with doxorubicin as described previously. Cell counts were done at 24,36 , and 72 hours.

\section{In Vivo Studies}

All the protocols were approved by the Wayne State University School of Medicine institutional review board. All the animals were housed and studied in a facility approved by the American Association for Accreditation of Laboratory Animal Care. Humane care was provided to all animals in accordance with the "Principles of Laboratory Animal Care" formulated by the National Society for Medical Research and the "Guide for the Care and Use of Laboratory Animals" prepared by the Institute of Laboratory Animal Resources, National Research Council, and published by the National Academy Press, revised 1996.

To determine the $\mathrm{Po}_{2}$ achieved in the pulmonary artery (PA), 7 Sprague-Dawley rats received pentobarbital anesthesia and were treated with $\mathrm{HBO}$ in the hyperbaric chamber with oxygen at $25 \mathrm{psi}$ for 30 minutes. Blood samples were collected from both arterial and PA sites by a catheter placed in a peripheral artery (carotid artery) and by a catheter placed at the base of the PA through a 19-gauge catheter through a thoracotomy. Blood gas samples were analyzed with an automated system (model 1312; Instrumentation Laboratories). The baseline values of $\mathrm{PO}_{2}$ and $\mathrm{PCO}_{2}$ both in the PA and at the arterial site were measured at time 0 and after 10 and 30 minutes of $\mathrm{HBO}$ administration in the chamber. Lungs of animals that received $\mathrm{HBO}$ were examined histologically.

For the aqueous oxygen method, Sprague-Dawley rats were anesthetized with pentobarbital, placed on mechanical ventilation, and subjected to left thoracotomy. A 19-gauge needle catheter was placed through the right ventricular outflow tract into the base of the PA. A 4F sheath was advanced through the transventricular catheter in the PA, and an aqueous oxygen solution containing 1.0 $\mathrm{mL}$ oxygen per gram of saline solution (3.4 MPa oxygen pressure) was infused directly into the PA at a rate of $1 \mathrm{~mL} / \mathrm{min}$. Blood samples were withdrawn from the catheter at time 0 to establish a baseline value and at 10 and 30 minutes after the aqueous oxygen treatment. The $\mathrm{PO}_{2}$ and $\mathrm{PCO}_{2}$ values in the PA were plotted. A 4-MHz prototype microbubble detector (ZEVEX International, Inc, Salt Lake City, Utah) mounted on the distal end of the circuit was used to detect microbubble formation.

Sprague-Dawley rats were randomly assigned to four different groups. The first group $(n=6)$ was injected at time 0 under pentobarbital anesthesia directly into the jugular vein with $1 \mathrm{~mL}$ of a suspension containing $1 \times 10^{6} \mathrm{MCA}-2$ cells $/ \mathrm{mL}$. At 14 days after the treatment, 3 of the animals were killed to assess the progression of the lung disease, and all the visible morphologic changes were noted. At 21 days the rest of the animals were killed, 


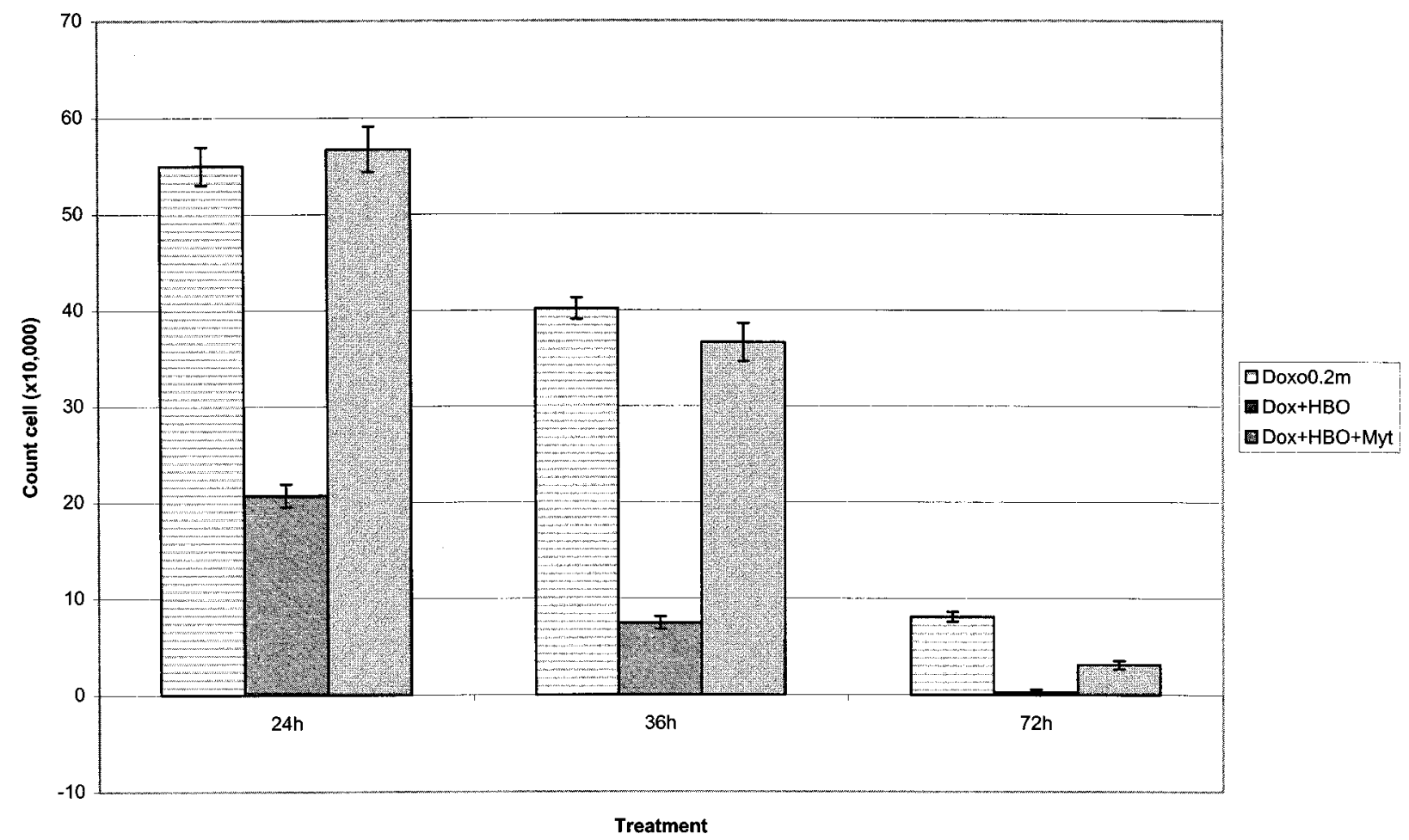

Figure 5. Mitomycin effect on sarcoma cells (MCA-2) treated with HBO and doxorubicin. Mitomycin blocks HBO-induced proliferation. There is no significant difference between doxorubicin-treated cells and cells treated with mitomycin before HBO and doxorubicin administration. Horizontal line fill, Doxorubicin only at $0.2 \mu \mathrm{mol} / \mathrm{L}$; gray fill, doxorubicin plus HBO; dotted fill, doxorubicin and HBO with mitomycin pretreatment.

and the number of lung nodules and the total lung weight were determined for each. The MCA-2 tumor cell line, developed by Nagashima and colleagues, ${ }^{15}$ is highly reproducible. All animals have bilateral lesions, and all die by 4 weeks. ${ }^{16}$

The second group $(n=6)$ was subjected to the same treatment with MCA-2 cells. At 14 days after the initial treatment, the animals were subjected to high levels of HBO (oxygen at 25 psi for 30 minutes). At 21 days after the initial treatment, these animals were also killed and the same parameters were measured.

The third group ( $\mathrm{n}=6$ ) was also subjected to MCA-2 administration. At 14 days, $2 \mathrm{mg} / \mathrm{kg}$ doxorubicin solution was given intrajugularly. At 21 days, the animals were killed and the same parameters were measured. The dose of doxorubicin given was the usual chemotherapeutic dose, which does not cause cardiotoxicity.

The fourth group $(n=6)$ was subjected to a combination of the previous two methods. At 14 days after the MCA- 2 cell administration, the animals were exposed to oxygen at 25 psi for 30 minutes and immediately thereafter to $2 \mathrm{mg} / \mathrm{kg}$ doxorubicin $(1 \mathrm{~mL})$ administered intrajugularly. At 21 days, the animals were killed and the same parameters as in the previous groups were determined.

\section{Postmortem Studies}

After 21 days, animals from all four treatment groups were killed to determine the effects of $\mathrm{HBO}$ on tumor growth and the efficacy of the HBO as a chemosensitizer to doxorubicin. The lungs were removed, and the total number of metastatic nodules in both lungs was determined and plotted. The total lung weight was also measured, and the results were compared with the average weight in the control group. The investigators were not blinded to the treatments at the time of analysis.

\section{Data Analysis}

An unpaired $t$ test assuming unequal variances was used to compare values across time with baseline values for both cell treatment groups and in vivo studies. Mean values are expressed as mean \pm 1.96 SE. For comparisons of more than two groups, a 2-way unbalanced analysis of variance was used, with a Bonferroni-type correction applied to $P$ values.

\section{Results}

\section{In Vitro Studies}

$\mathrm{HBO}$ exerted a toxic effect on $\mathrm{H} 9 \mathrm{C} 2$ cells (rat embryonic cardiac myocytes), as reflected in a descending growth curve relative to cells cultured in air. The difference was statistically significant at 24 hours $\left(10.809 \pm 1.861 \times 10^{4}\right.$ cells vs $5.7142 \pm 0.714 \times 10^{4}$ cells, $\left.P<.01\right)$ and at 36 hours $\left(14.809 \pm 1.761 \times 10^{4}\right.$ cells vs $3.9523 \pm 0.847 \times 10^{4}$ cells, $P<.01$; Figure 1 ). MCA-2 cells (rat-derived rhabdomyosarcoma) exhibited biphasic behavior. At 40 psi for 


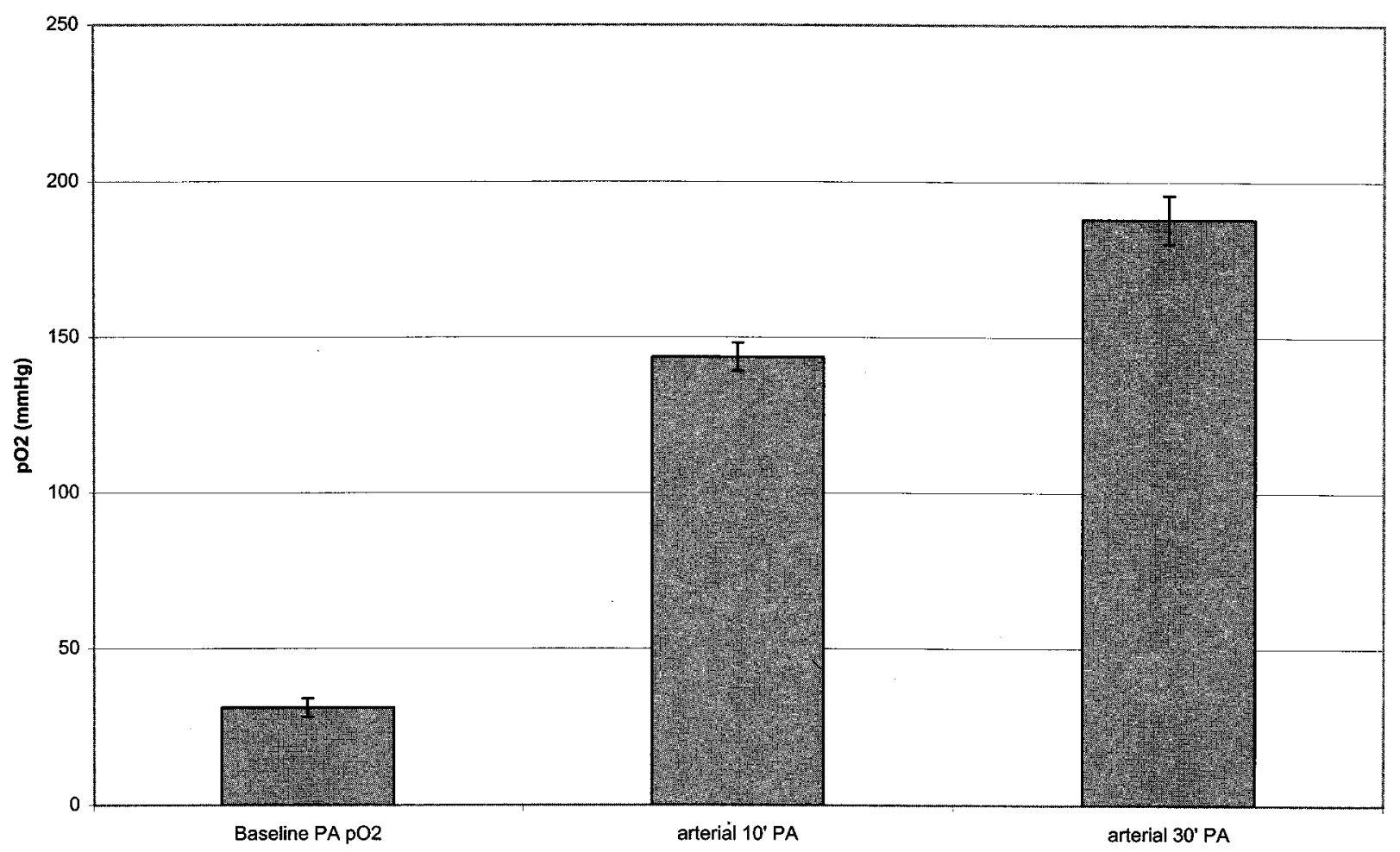

Figure 6. $\mathrm{PA} \mathrm{Po}_{2}$ after $\mathrm{HBO}$ administration by hyperbaric chamber. Note increases in $\mathrm{PA} \mathrm{Po}_{2}$ at $10\left(10^{\prime}\right)$ and 30 minutes $\left(30^{\prime}\right)$ relative to baseline.

1.5 hours, $\mathrm{HBO}$ was associated with an early proliferative response (at 24 hours $188.0769 \pm 44.633 \times 10^{4}$ cells with no treatment vs $305.384 \pm 110.406 \times 10^{4}$ cells treated with HBO, $P<.01$; Figure 2). At longer durations of HBO, loss of cell viability was observed (at 24 hours $168.03 \pm$ $20.838 \times 10^{4}$ cells treated with oxygen at 40 psi for 2.5 hours and $109.445 \pm 11.675 \times 10^{4}$ cells treated with oxygen at 40 psi for 3.5 hours).

Doxorubicin was toxic to both $\mathrm{H} 9 \mathrm{C} 2$ and MCA-2 cells at even a minimal dose $(0.1 \mu \mathrm{mol} / \mathrm{L})$, and cell death increased in a dose-dependent manner for both cell populations. LDH levels had corresponding increases at higher doses of doxorubicin (Figure 3, $A-D$ ).

MCA-2 cells treated with oxygen at 40 psi for 1.5 hours and $0.1-\mu \mathrm{mol} / \mathrm{L}$ doxorubicin exhibited enhanced lysis $\left(18.642 \pm 2.247 \times 10^{4}\right.$ cells, corresponding to an average viability of $42 \%$ ) relative to cells treated with either 0.1 $\mu \mathrm{mol} / \mathrm{L}$ doxorubicin alone $\left(29.9 \pm 11.6 \times 10^{4}\right.$, average viability $70 \%, P<.01$ ) or longer $\mathrm{HBO}$ (oxygen at $40 \mathrm{psi}$ for 3.5 hours $)$ and $0.1-\mu \mathrm{mol} / \mathrm{L}$ doxorubicin $\left(8.4 \pm 0.7 \times 10^{4}\right.$ cells, average $50 \%$ viability, $P<.01$; Figure 4 ).

Mitomycin blocked the proliferative effect associated with oxygen at 40 psi for 1.5 hours. Sarcoma cell death with $0.1 \mu \mathrm{mol} / \mathrm{L}$-doxorubicin was not significantly different from the group treated with mitomycin and HBO plus doxorubicin (at 24 hours, $55 \pm 10.2 \times 10^{4}$ cells vs $56.72 \pm$ $14.61 \times 10^{4}$ cells, $P=.7935$; Figure 5).

\section{In Vivo Animal Studies}

Oxygen tensions. The $\mathrm{PA} \mathrm{PO}_{2}$ values in the mixed $\mathrm{PA}$ venous blood obtained after $\mathrm{HBO}$ treatment with oxygen at 25 psi were higher $(143.642 \pm 71.478 \mathrm{~mm} \mathrm{Hg}$ at 10 minutes and $187.92 \pm 20.268 \mathrm{~mm} \mathrm{Hg}$ at 30 minutes) than the baseline $\mathrm{Po}_{2}(44.23 \pm 3.645 \mathrm{~mm} \mathrm{Hg}$ ) (Figure 6). The mean $\mathrm{PaO}_{2}$ achieved similar directional changes (411.54 \pm 59.65 $\mathrm{mm} \mathrm{Hg}$ after 30 minutes vs $91.254 \pm 15.263 \mathrm{~mm} \mathrm{Hg}$ baseline). No microscopic injuries were noted in the lungs of the animals that received $\mathrm{HBO}$. The $\mathrm{PA} \mathrm{Po}_{2}$ values obtained after aqueous oxygen infusion were comparable to those seen after HBO administration (140.224 \pm 16.22 at 10 minutes of aqueous oxygen infusion in the PA and $211 \pm$ 5.0 at 30 minutes). The same results were obtained for $\mathrm{PaO}_{2}$ values after aqueous oxygen infusion (156.071 \pm 17.7609 $\mathrm{mm} \mathrm{Hg}$ for 5 minutes of aqueous oxygen infusion and $392.714 \pm 75.606 \mathrm{~mm} \mathrm{Hg}$ for 10 minutes vs baseline value $90.2 \pm 4.2 \mathrm{~mm} \mathrm{Hg}$ ).

Metastases. The mean number of metastases in group 1 (tumor cells only), $73.1666 \pm 12.166$ metastases, was significantly greater than the numbers of metastases in group 3 
In vivo response to Doxo $+/-\mathrm{HBO}$
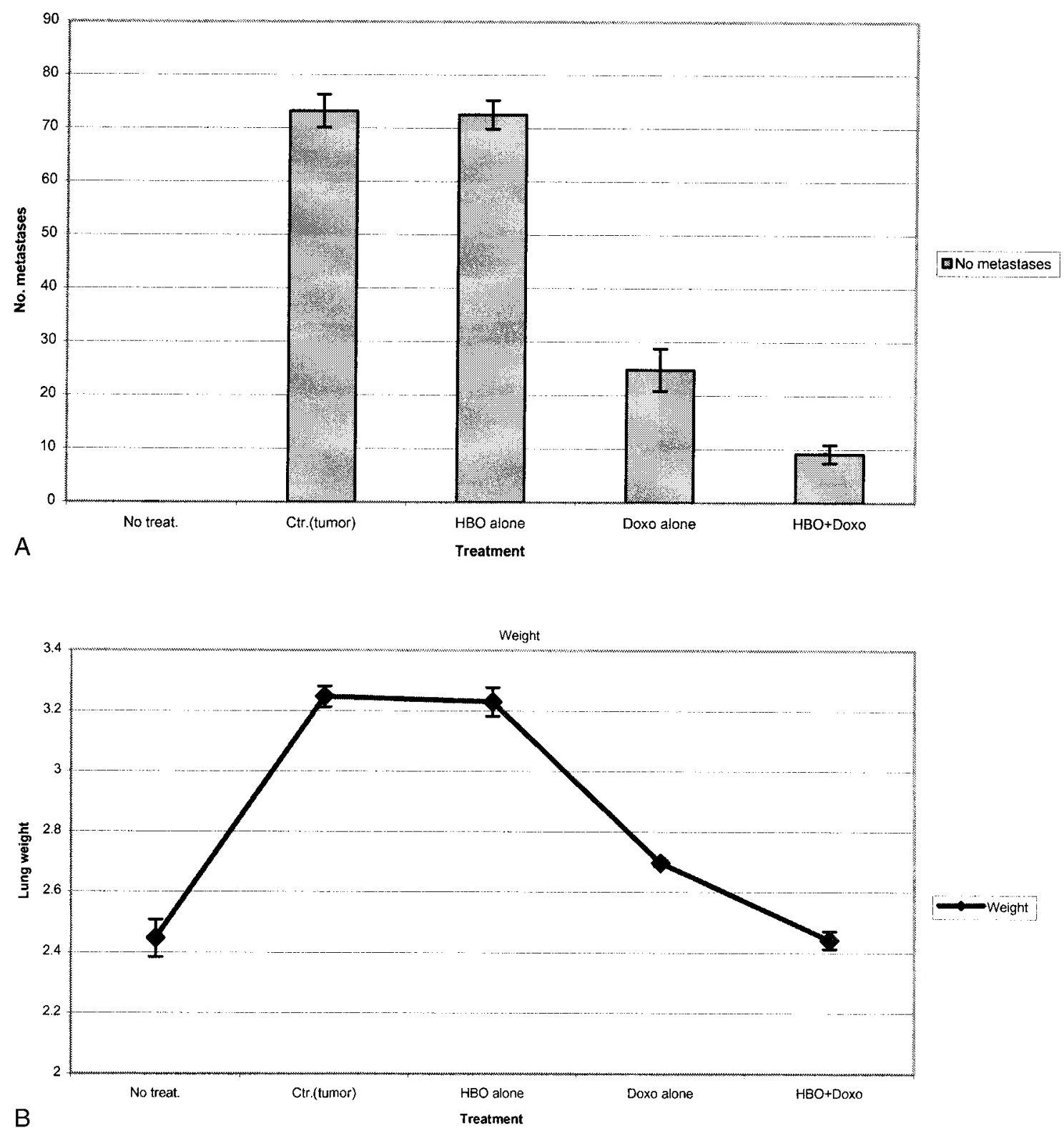

Figure 7. In vivo response to doxorubicin and $\mathrm{HBO}$ in rat metastatic lung sarcoma model. A, Number of metastases per individual lung decreased significantly when treated with doxorubicin (Doxo) alone and then had significant further decrease when treated with HBO and doxorubicin. B, Changes in individual lung weights correspond with decreases in metastatic tumor nodules. No treat., No treatment; Ctr, control.

(doxorubicin only), $24.833 \pm 20.566$ metastases $(P<.01)$, and group 4 (HBO before doxorubicin), $9.16 \pm 3.76$ metastases $(P<.01$; Figure $7, A)$. Similarly, mean lung weight was significantly higher in group $1(3.247 \pm 0.0015 \mathrm{~g})$ than in group $3(2.696 \pm 0.0001 \mathrm{~g}, P<.01)$ and group $4(2.441 \pm$ $0.0001 \mathrm{~g}, P<.01$; Figure $7, B$ ). HBO only (group 2 ) was not associated with significant changes in the number of nodules $(72.5 \pm 9.5, P<.7329)$ and average lung weight $(3.23 \pm$ $0.002 \mathrm{~g}, P<.5483$ ) relative to group 1 . HBO before doxorubicin (group 4) was associated with significant decreases in both the number of nodules $(P<.01)$ and the mean lung weight $(P<.01)$ relative to doxorubicin alone (group 3$)$. 


\section{Discussion}

$\mathrm{HBO}$ at 3.7 atm absolute for 1.5 hours sensitized a rhabomyosarcoma cell line (MCA-2) to the cytotoxic effects of doxorubicin, including the lowest level of the drug examined $(0.1 \mu \mathrm{mol} / \mathrm{L})$. HBO also enhanced the in vivo chemotherapeutic response of MCA-2 metastatic lung tumors to doxorubicin in terms of both the number of tumors and lung weight 2 weeks after treatment.

At the $0.1-\mu \mathrm{mol} / \mathrm{L}$ drug level studied in cell culture, only mild toxicity to cardiomyocytes (H9C2) was observed under normoxic conditions. Considering the toxicity to cardiomyocytes of HBO (3.7 atm absolute for 1.5 hours) itself in our study and the known role of oxygen radicals in doxorubicin cardiotoxicity, the combination of doxorubicin and HBO would also be expected to enhance the drug's cardiotoxicity. In a potentially relevant study, Monstrey and associates ${ }^{17}$ demonstrated experimentally that $\mathrm{HBO}$ does enhance oxygen-derived free radical-mediated toxicity of doxorubicin to other normal tissues. Thus the clinical addition of $\mathrm{HBO}$ to doxorubicin may not change the risk-benefit ratio of the drug.

However, regional HBO treatment provided with aqueous oxygen infusion can be used in a highly site-specific manner to avoid elevating systemic oxygen levels. Such an approach might allow the use of doxorubicin at levels that produce minimal cardiotoxicity. Although regional infusion of a chemotherapeutic agent can be performed, exposure of systemic tissues to the agent will nevertheless occur.

The mechanism through which $\mathrm{HBO}$ potentiated the toxic effects of doxorubicin in our studies is unclear. Oxygen radical production may be enhanced, but the relationship between $\mathrm{PO}_{2}$ and generation of oxygen radicals may be quite complex, as has been shown by DeGroot and Noll. ${ }^{18}$

As an alternative mechanism, perturbation of the cell cycle of prostate cancer cells by HBO, with cell cycle synchronization and entry into $G_{2}$ and $M$ phases, was found by Kalns and Piepmeier ${ }^{19}$ and suggested to potentially increase the efficacy of chemotherapy or radiation. The cause for proliferation of MCA-2 cells in this study is unknown. One hypothesis is that $\mathrm{HBO}$ acts as a second messenger to speed entry into $G_{2}$ and $M$ phases. In this study, stimulation of MCA-2 cells by HBO (3.7 atm absolute for 1.5 hours) caused cells to proliferate earlier than cells grown in air. The fact that enhancement of sensitivity to doxorubicin was found to occur after rather than during $\mathrm{HBO}$ exposure provides some support for this concept. Perhaps even more relevant, mitomycin, an agent that inhibits cell proliferation, reduced $\mathrm{HBO}$ enhancement of doxorubicin toxicity to MCA- 2 cells. In addition, there was no increase in cell death when $\mathrm{HBO}$ was given after doxorubicin.

Under hyperbaric conditions, the $\mathrm{PO}_{2}$ of mixed venous blood can approach normal levels for $\mathrm{PaO}_{2}$, as we found in our in vivo study. Similarly high levels were achievable with aqueous oxygen infusion into the PA. The potential exists for aqueous oxygen infusion into mixed venous blood to enhance $\mathrm{Po}_{2}$ to levels even higher than those of arterial samples during HBO. Therefore the potential use of the new technology to attenuate hypoxia within lung tumors perfused by mixed venous blood and to enhance drug or radiation therapy is attractive.

Isolated perfusion studies by Weksler and coworkers ${ }^{20}$ with higher doses of doxorubicin than in this model demonstrated significant decreases in tumors per lung. Combining $\mathrm{HBO}$ with high-dose doxorubicin offers the possibility of an additive effect of $\mathrm{HBO}$ to the standard doxorubicin dose.

\section{Conclusion}

At certain concentrations (1.5 hours at $40 \mathrm{psi}$ ) $\mathrm{HBO}$ enhanced the proliferation of rat rhabdomyosarcoma cells in vitro. HBO also increased the tumoricidal action of doxorubicin. Doxorubicin could be used in conjunction with $\mathrm{HBO}$ to obtain the same effect as higher doxorubicin doses.

The chemosensitizing effect of $\mathrm{HBO}$ was reproduced in a metastatic rat lung tumor model. High levels of oxygen enhanced chemotherapy action, probably by stimulating tumor growth. Increased oxygen can oxygenate mixed venous blood (in the PA) to levels similar to those achieved by use of a hyperbaric chamber. Aqueous oxygen is a potential method to raise the oxygen level to arterial levels in the PA and to hyperbaric levels in the remainder of the body. With this hyperbaric cell effect, aqueous oxygen could enhance the effect of regional or systemic chemotherapy in vivo.

\section{References}

1. Rochitte CE, Lima JA, Bluemke DA, Reeder SB, McVeigh ER, Furuta $\mathrm{T}$, et al. Magnitude and time course of microvascular obstruction and tissue injury after acute myocardial infarction. Circulation. 1998;98: 1006-14.

2. Wu KC, Kim RJ, Bluemke DA, Rochitte CE, Zerhouni EA, Becker $\mathrm{LC}$, et al. Quantification and time course of microvascular obstruction by contrast-enhanced echocardiography and magnetic resonance imaging following acute myocardial infarction and reperfusion. $J \mathrm{Am}$ Coll Cardiol. 1998;32:1756-64.

3. Kloner RA, Ganote CE, Jennings RB. The "no-reflow" phenomenon after temporary coronary occlusion in the dog. J Clin Invest. 1974; 54:1496-508.

4. Jeremy RW, Links JM, Becker LC. Progressive failure of coronary flow during reperfusion of myocardial infarction: documentation of the no reflow phenomenon with positron emission tomography. $J \mathrm{Am}$ Coll Cardiol. 1990;16:695-704.

5. Weinstein H, Reinhard CP, Leppo JA. Direct detection of regional myocardial ischemia with technetium-99m nitroimidazole in rabbits. J Nucl Med. 1998;39:598-607.

6. Ince C, Vink H, Wieringa PA, Giezeman M, Spaan JA. Heterogeneous NADH fluorescence during post-anoxic reactive hyperemia in saline perfused rat heart. Adv Exp Med Biol. 1990;277:477-82.

7. Wu KC, Zerhouni EA, Judd RM, Lugo-Olivieri CH, Barouch LA, Schulman SP, et al. Prognostic significance of microvascular obstruction by magnetic resonance imaging in patients with acute myocardial infarction. Circulation. 1998;97:765-72.

8. McCord J. Oxygen-derived radicals: a link between reperfusion injury and inflammation. Fed Proc. 1987;46:2402-6.

9. DeFily DV. Control of microvascular resistance in physiological conditions and reperfusion. J Mol Cell Cardiol. 1998;30:2547-54. 
10. Spears JR. Advances in the management of respiratory failure: aqueous preparations of oxygen. ASAIO J. 1996;42:196-8.

11. Spears JR, Wang B, Wu X, Prcevski P, Jiang AJ, Spanta AD, et al. Aqueous oxygen: a highly $\mathrm{O}_{2}$-supersaturated infusate for regional correction of hypoxemia and production of hyperoxemia. Circulation. 1997;96:4385-91.

12. Timm M, Hornig J, von Baehr R. Dye exclusion test and LDH release assay. Allerg Immunol (Leipz). 1982;28:64-9.

13. Legrand C, Bour JM, Jacob C, Capiaumont J, Martial A, Marc A, et al. Lactate dehydrogenase (LDH) activity of the cultured eukaryotic cells as marker of the number of dead cells in the medium. J Biotechnol. 1992;25:231-43.

14. Lobner D. Comparison of the LDH and MTT assays for quantifying cell death: validity for neuronal apoptosis? J Neurosci Meth. 2000;96: 147-52.

15. Nagashima A, Yasumoto K, Nakahashi H, Furukawa T, Inokuchi K, Nomoto K. Establishment and characterization of high and lowmetastatic clones derived from a methylcholanthrene-induced rat fibrosarcoma. Cancer Res. 1986;46:4420-4.

16. Weksler B, Schneider A, Ng B, Burt ME. Isolated singled lung perfusion in the rat: an experimental model. J Appl Physiol. 1993;74: 2736-8.

17. Monstrey SJ, Mullick P, Narayanan K, Ramasastry SS. Hyperbaric oxygen therapy and free radical production: an experimental study in doxorubicin (Adriamycin) extravasation injuries. Ann Plast Surg. 1997;38:163-8.

18. DeGroot H, Noll T. The role of physiological oxygen partial pressures in lipid peroxidation: theoretical consideration and experimental evidence. Chem Phys Lipids. 1987;44:209-26.

19. Kalns JE, Piepmeier EH. Exposure to hyperbaric oxygen induces cell cycle perturbation in prostate cancer cells. In Vitro Cell Dev Biol Anim. 1999;35:98-101.

20. Weksler B, Lenert J, Ng B, Burt M. Isolated single lung perfusion with doxorubicin is effective in eradicating soft tissue sarcoma lung metastases in a rat model. J Thorac Cardiovasc Surg. 1994;107:50-4.

\section{Discussion}

Dr G. Alexander Patterson (St Louis, Mo). I did not understand exactly how you created that hyperbaric situation in vivo. Some animals were treated in a hyperbaric chamber whereas others had this infusion technique?

Dr Baciewicz. With regard to the animals that were administered tumor cells, gave hyperbaric levels of oxygen on day 14 . These animals were quite ill, so we administered the oxygen by the hyperbaric chamber technique. We had hoped to use the aqueous oxygen technique for those animals, but it was difficult to place a 4F catheter into the PA, especially when all these animals were dead 7 days later. We were not able to do what we had hoped. We did demonstrate with the aqueous oxygen technique that we could obtain the same levels of oxygen in the pulmonary as with the hyperbaric chamber. We need a larger animal model to look further at this. The aqueous oxygen has already been used for patients with myocardial infarction, with infusion into left coro- naries and right coronaries, with good phase I data. We should be able to duplicate the aqueous oxygen technique in a different model.

Dr Stephen G. Swisher (Houston, Tex). I saw some nice differences there. Did you look at this statistically as well?

Dr Baciewicz. Yes.

Dr Swisher. Was it statistically significant?

Dr Baciewicz. Yes, it was statistically significant.

Dr David H. Harpole, Jr (Durham, NC). I have a follow-up question. Obviously, poor perfusion is a major problem with respect to getting the chemotherapy to the hypoxic areas of the tumor. In addition, one needs oxygen to create the free radicals for the DNA damage from radiation therapy to induce apoptosis and cell death. So have you thought about using this as a radiation adjunct? I think it would have a tremendous effect. Carbogen breathing, if you are familiar with those studies, has shown increased efficacy for radiation therapy, so I think that this also would have a use in that field.

Dr Baciewicz. Thanks for the question. That was actually the main idea for the project, that radiosensitivity would be tremendously increased by delivering hyperbaric levels of oxygen or increased oxygen to the lung. We are about to start those studies. Work with isolated lung perfusion and doxorubicin has been done in this tumor model. So we are hoping to put all three things together. It is difficult in our institution to give radiation therapy and HBO to these animals. That was our original intent for the study. This work with the chemotherapeutic agent was a spin-off, and we are hoping to get the radiation part going soon. It is an excellent question.

Dr Peter Goldstraw (London, United Kingdom). We know that the pulmonary toxicity of chemotherapeutic agents can be enhanced by increasing inspired oxygen concentrations, which is not surprising given the central role of reactive oxygen species in the generation of adult respiratory distress syndrome. This could possibly limit the clinical safety of this sort of technique. Have you done any studies looking at acute lung injury and capillary permeability in the lungs of these animals undergoing this combined treatment?

Dr Baciewicz. You are absolutely right. If you give the animals too much oxygen, you are obviously going to cause injury from the oxygen itself. The 1.5-hour period looks to be an optimal amount of time for treatment. I did not show any histologic images from the animals that were treated in this study, but the lung tissue looked normal on histopathologic examination. So we know that 1.5 hours is an acceptable time, but certainly the method of oxygen administration and the ideal duration remain to be determined. 